\section{Integrating mental health in global initiatives}

\section{for HIV/AIDS}

\author{
MELVYN C. FREEMAN, VIKRAM PATEL, PAMELA Y. COLLINS \\ and JOSE M. BERTOLOTE
}

\begin{abstract}
Summary A more prominent role is needed for mental health interventions in global HIV/AIDS initiatives - such as the World Health Organization ' 3 by 5 ' Initiative. Significant numbers of infected people have, or develop, mental health problems, and this often adversely impacts on HIV/AIDS treatment and adherence. Integrating psychiatric and psychosocial interventions should benefit both the mental and the physical health of people living with HIV/AIDS.
\end{abstract}

\section{Declaration of interest None.}

One of the most pressing international health problems of our time is HIV/AIDS. In 2004 an estimated 39.4 million people were living with HIV and over 3 million people died of the disease (UNAIDS, 2004). Preventing the spread of the pandemic and providing treatment to infected individuals - especially in developing countries - present vexing challenges, despite increased understanding of the risk factors of the condition and the development of improved and less burdensome treatment regimens. Of the 6 million people globally who require antiretroviral therapy, only $8 \%$ receive it - with considerable geographical inequity. For example, in the region of the Americas $84 \%$ of persons needing antiretroviral therapy receive this treatment, whereas in Africa only $2.2 \%$ of an estimated 4.4 million in need do so (World Health Organization, 2003). Millions continue to die unnecessarily, with not only devastating consequences at a personal and family level, but also major social and economic consequences. In September 2003, this dire situation prompted Lee Jong-Wook, Director-General of the World Health Organization (WHO), Peter Piot, Executive Director of UNAIDS, and Richard Feachem, Executive Director of the Global Fund to Fight AIDS, Tuberculosis and Malaria, jointly to declare the lack of access to antiretroviral drugs to be a global health emergency. Together they launched the 'Treat 3 Million by 2005' ('3 by 5') Initiative (World Health Organization, 2003).

The emphasis of these new initiatives has been, to a large extent, focused on ensuring the reliable and proper provision of evidence-based antiretroviral treatments. In July 2004, a group of 18 mental health professionals (see Appendix) from developed and developing countries met in Johannesburg, South Africa, under the auspices of the WHO. The group's task was to consider how mental health should be integrated into the ' 3 by 5 ' to support the programme's goals and objectives. This editorial presents the key themes arising from this meeting. These themes and recommendations emphasise the role of, and opportunities for, mental health issues in global initiatives for HIV care and treatment in developing countries.

\section{WHY MENTAL HEALTH MATTERS TO HIV/AIDS TREATMENT PROGRAMMES IN DEVELOPING COUNTRIES}

Four major questions were considered to make the case for the integration of mental health into HIV/AIDS treatment programmes.

First, why are concerns about mental health relevant for people with HIV/AIDS? We identified at least five distinct mental health-related issues that would be relevant to HIV/AIDS programmes: cognitive impairment and dementia due to viral infection of the brain; depression and anxiety due to the impact of the infection on the person's life; alcohol and drug use, which contribute to risk behaviours; the psychiatric side-effects of some antiretroviral therapy (notably efavirenz); and the social difficulties faced as a result of stigma and discrimination (Chandra et al, 1998; Els et al, 1999; Tostes et al, 2004). A significant proportion of people with HIV/AIDS in some developed countries receive some form of psychosocial and/or mental health intervention, including psychotropic medication, psychotherapy and other services (Vitiello et al, 2003; Green \& Smith, 2004). We lack data from developing countries on how many people with HIV/AIDS seek mental health services and receive treatment, but anecdotal evidence suggests that only a small number of HIV treatment programmes in these settings provide mental health services, and only a fraction of those with HIV/AIDS receive mental healthcare.

The second question is whether providing mental health interventions improves the medical and treatment outcomes of people with HIV/AIDS. Would the expected improvement in mental health outcomes (such as reduced rates of depression) influence the course and outcome of the viral disease? Ickovics et al (2001) have demonstrated that depressive symptoms in women with HIV are associated with disease progression. Moreover, the success of HIV treatment programmes requires that participants adhere to long-term therapy with multiple drugs, some of which may produce unpleasant side-effects. Numerous studies have found that mental disorders are a significant impediment to adherence to antiretroviral therapy (Hinkin et al, 2002; Ammassari et al, 2004). In addition to the treatment of specific mental disorders, several behavioural interventions derived from mental health practice may also contribute to adherence. These include motivational interviewing, cognitivebehavioural therapy and group supportive therapy (Ironson et al, 2005; Parsons et $a l, 2005)$. A recent study from Peru, for example, demonstrated how group therapy could improve adherence to treatment for tuberculosis in patients with multidrug-resistant tuberculosis (Sweetland et al, 2002).

Thus, mental health issues are closely associated with the experience of living with HIV/AIDS and with the course and management of the disease. The third question is whether providing mental health interventions is feasible. Specifically, can these interventions be provided in settings that are already desperately short of mental 
health resources? Two opportunities are evident. First, the roll-out of the ' 3 by 5 ', initiative involves intensive and widespread training in the WHO Integrated Management of Adolescent and Adult Illnesses (IMAI) (World Health Organization, 2004); by including mental health in the IMAI guidelines and ensuring adequate training in basic medical and psychological management of disorders, a holistic and integrated primary mental healthcare approach can be promoted. Moreover, we believe that, in the case of HIV/AIDS, there is already a substantial human resource base among the primary care providers who are ideally placed to provide front-line mental healthcare in the ' 3 by 5 ' initiative. These providers are the growing number of HIV/AIDS counsellors being trained in most developing countries to conduct primarily pre-test and post-test counselling as part of voluntary counselling and testing programmes (Kaaya \& Fawzi, 1999). These counsellors, who come from a variety of educational backgrounds and health disciplines, are trained in counselling skills such as giving information, listening to the personal concerns and worries of the person with HIV/AIDS, and problem-solving. Counsellors recognise that many people will develop adverse emotional reactions in response to testing, and the counselling is partly aimed at minimising these reactions. Mental disorders encompass a continuum from mild distress to frank clinical conditions, and some HIV counsellors may already possess the skills to manage the milder emotional problems (Vollmer \& Valadez, 1999).

Finally, what is the potential impact on the status of mental healthcare in developing countries of a substantive, vertical, disease-focused programme such as the ' 3 by 5 ' initiative? We believe that the integration of mental health into this initiative presents an enormous opportunity to strengthen the status of mental health in public health services in developing countries. It provides an important chance to improve the health of people with HIV specifically, and to expand mental health services in general health services. These actions would increase the mental health resource base in many countries several-fold (by including general health workers and counsellors as de facto mental health personnel) and increase the awareness of the burden and management of mental disorders in the general health sector.

\section{RECOMMENDATIONS}

Three broad recommendations were made for the integration of mental health in the ' 3 by 5 ' and other HIV/AIDS treatment programmes in developing countries.

First, a successful HIV/AIDS intervention programme must include the assessment of mental disorders and their appropriate management as part of the normative service. There is a need to develop appropriate materials and models for the delivery of mental healthcare within the parameters of the ' 3 by 5 ' initiative based on the principles of affordability, acceptability and availability. The front-line providers should be the existing primary healthcare workers and counsellors who have received additional training and relevant materials - although caution is needed so that too many functions are not expected of the same individuals. Additional skilled personnel may be essential in certain situations. When possible, an established relationship with local mental health service providers should be encouraged, to promote a collaborative model of care that includes supervision and support for the firstlevel workers as well as clearly defined referral pathways to specialist services.

The second recommendation is the need to support research on mental health and HIV/AIDS. Despite the fact that over $90 \%$ of the burden of HIV/AIDS is in developing countries, little research in this area emerges from these countries. We recommend that the immediate priorities for research must be linked to the new treatment programmes. Two key research questions were identified: what is the impact of mental disorders on the course and outcome of HIV/AIDS and the efficiency of the antiretroviral therapy programmes (for example, immune status indicators, adherence with therapy); and what is the feasibility, effectiveness and cost-effectiveness of mental health interventions?

Finally, advocacy is needed from a range of stakeholders to highlight the role of mental health in HIV/AIDS treatment programmes. Sadly, although such programmes are well recognised in developed countries, mental health perspectives are notable only for their absence in the programmes being rolled out in developing countries. The incremental cost of such a component is likely to be a fraction of the total programme cost. Moreover, people accessing HIV/AIDS services must demand mental health services to ensure that these are prioritised by agencies implementing treatment programmes.

The ' 3 by 5 ' initiative is a massive response by the WHO to an enormous global health crisis. Its implementation (and its undoubted continuation in some form) must include effective alleviation of psychiatric symptoms and promote the emotional well-being of people living with HIV/AIDS.

\section{APPENDIX}

The following mental health professionals attended the ' 3 by 5 and Mental Health' meeting in Johannesburg in 2004, and contributed to the strategic analysis and work plan:

Dr Atalay Alem (Ethiopia), Dr Jose Bertolote (WHO), Dr Jose Catalan (UK), Dr Pamela Collins (USA), Dr Francine Cournos (USA), Professor Melvyn Freeman (South Africa/WHO), Dr Sandy Gove (WHO), Dr Mark Halman (Canada), Dr Kevin Kelly (South Africa), Ray Lazarus (South Africa), Dr Joseph Mbatia (Tanzania), Professor Dan Mkize (South Africa), Dr Vikram Patel (India), Kerry Saloner (South Africa), Vernon Solomon (South Africa), Professor Leslie Swartz (South Africa), Annika Sweetland (USA/Peru), Dr Rita Thom (South Africa).

\section{REFERENCES}

Ammassari, A., Antinori, A., Aloisi, M. S., et al (2004) Depressive symptoms, neurocognitive impairment, and adherence to highly active antiretroviral therapy among HIV-infected persons. Psychosomatics, 5, 394-402.

Chandra, P. S., Ravi, V., Desai, A., et al (1998) Anxiety and depression among HIV-infected heterosexuals a report from India. Journal of Psychosomatic Research $\mathbf{4 5}$, 40I-409.

Els, C., Boshoff, W. \& Scott, C. (1999) Psychiatric co-morbidity in South African HIV/AIDS patients. South African Medical Journal, 89, 992-995.

Green, G. \& Smith, R. (2004) The psychosocial and healthcare needs of HIV positive people in the United Kingdom: a review. HIV Medicine, 5 (suppl. I), 5-46.

Hinkin, C. H., Castellon, S. A., Durvasula, R. S., et al (2002) Medication adherence among HIV+ adults: effects of cognitive dysfunction and regimen complexity. Neurology, 59, 1944-1950.

Ickovics, J. R., Hamburger, M. E., Vlahov, D., et al (200I) Mortality, CD4 cell count decline, and depressive symptoms among HIV-seropositive women. JAMA, $\mathbf{2 8 5}$, 1466-1474.

Ironson, G., Weiss, D., Lydston, D., et al (2005) The impact of improved self-efficacy on HIV viral load and distress in culturally diverse women living with AIDS: the SMART/EST Women's Project. AIDS Care, 17, 222-236

Kaaya, S. F. \& Fawzi, M. C. (1999) HIV counseling in sub-Saharan Africa. Aids, 13, 1577-1579.

Parsons, J.T., Rosof, E., Punzalan, J. C., et al (2005) Integration of motivational interviewing and cognitive behavioural therapy to improve HIV medication adherence and reduce substance use among HIV- 
positive men and women: results of a pilot project. AIDS Patient Care and STDs, 19, 31-39.

\section{Sweetland, A., Albujar, J. A. \& Echevarria, D. G.}

(2002) Enhancing adherence: the role of group

psychotherapy in the treatment of MDR-TB in urban

Peru. In World Mental Health Casebook: Social and Mental

Health Programmes in Low-income Countries (eds

A. Cohen, A. Kleinman \& B. Saraceno), pp. 5I-79. New

York: Kluwer Academic/Plenum.

Tostes, M. A., Chalub, M. \& Botega, N. J. (2004) The quality of life of HIV-infected women is associated with psychiatric morbidity. AIDS Care, 16, 177-186.

UNAIDS (2004) 2004 Report on the Global AIDS Epidemic. Geneva: UNAIDS.

Vitiello, B., Burman, M. A., Bing, E. G., et al (2003) Use of psychotropic medications among HIV-infected

MELVYN FREEMAN, MA (Clin Psych), Chief Research Specialist, Human Sciences Research Council, Pretoria, South Africa; VIKRAM PATEL, MRCPsych, PhD, Reader in International Mental Health, London School of Hygiene and Tropical Medicine, UK; PAMELAY. COLLINS, MD, MPH, Assistant Professor of Clinical Psychiatry in Epidemiology, Departments of Psychiatry and Epidemiology, Columbia University, New York State Psychiatric Institute, USA; JOSE BERTOLOTE, MD, Coordinator, Management of Mental and Brain Disorders, Department of Mental Health and Substance Abuse, Geneva, Switzerland

Correspondence: Professor Melvyn C. Freeman, Human Sciences Research Council, Private Bag X4I, Pretoria 000I, South Africa.E-mail: mfreeman@hsrc.ac.za

(First received 3 December 2004, final revision 3 March 2005, accepted 7 March 2005)

patients in the United States. American Journal of Psychiatry, 160, 547-554.

Vollmer, N. A. \& Valadez, J. J. (1999) A psychological epidemiology of people seeking HIV/AIDS counselling in Kenya: an approach for improving counsellor training. Aids, I3, I557-1567.
World Health Organization (2003) Treating 3 Million By 2005. Making it Happen. The WHO Strategy. Geneva: WHO.

World Health Organization (2004) Integrated Management of Adolescent and Adult Illness. Acute Care; Chronic HIV Care with ARV Therapy. Geneva: WHO. 